\title{
DYNAMIC NUMERICAL SIMULATION OF STEEL FRAME-TYPED PIERS INSTALLED WITH SMA DAMPING DEVICES BASED ON MULTI-LINEAR ONE DIMENSIONAL CONSTITUTIVE MODEL
}

\author{
Xiao-Qun Luo ${ }^{1,2}$, Hanbin $\mathrm{Ge}^{3,{ }^{*}}$ and Tsutomu Usami ${ }^{4}$ \\ 1 Post doctoral researcher, Advanced Research Center for Seismic Experiments and Computations, Meijo University \\ Shiogamaguchi, Tempaku-ku, Nagoya, 468-8502, Japan \\ ${ }^{2}$ Lecturer, Department of Building Engineering, Tongji University, No. 1239, Sipin Road, Shanghai, 200092, China. \\ ${ }_{3}^{3}$ Professor, Dept. of Civil Engineering, Meijo University \\ Shiogamaguchi,Tempaku-ku, Nagoya,468-8502,Japan.Email: gehanbin@meijo-u.ac.jp \\ ${ }^{4}$ Professor, Dept. of Civil Engineering, Meijo University \\ Shiogamaguchi, Tempaku-ku, Nagoya, 468-8502, Japan.Email: usamit@meijo-u.ac.jp \\ *(Corresponding author: E-mail: gehanbin@meijo-u.ac.jp)
}

Received: 10 February 2009; Revised: 13 July 2009; Accepted: 10 August 2009

\begin{abstract}
In this paper, the effectiveness of seismic performance upgrading is studied by adoption of damping devices made of shape memory alloys (SMAs). An axial-type SMA damper is constructed and modeled on the basis of a modified multi-linear one dimensional constitutive model of SMAs. Time history analyses are carried out on typical steel frames with SMA damping devices. Performance parameters for seismic performance upgrading are investigated in consideration of four influence factors, i.e., strength ratio, martensite fraction, length ratio, and ground motion. Dynamic analyses of bare frames and frames with equivalent BRB dampers are also conducted for comparisons. Numerical investigations show that excellent re-centering ability and energy dissipation can be afforded by installing SMA damping devices in structures.
\end{abstract}

\section{INTRODUCTION}

Damping devices are usually applied for suppression of undesired structural vibrations under severe loadings such as strong earthquake motions. With development of new materials and new control techniques, many damping devices are developed such as viscous dampers, visco-elastic dampers, friction dampers, hysteretic metal dampers, shape memory alloy dampers and so on Weber et al. [1].

Due to their shape memory effect and super-elasticity, shape memory alloys (SMAs) can undergo large deformations over $10 \%$ and return to their original shape without residual deformations through heat process or removal of load. Recently, besides applications in biomedical field, aerospace field, etc., more attentions are also received for SMAs seismic applications in the field of civil and building engineering because of their intelligent characteristics such as re-centering, energy dissipating, damping and so on. Various damping devices and isolation devices were proposed by many researchers. For examples, two families of passive seismic control devices, i.e., special frame braces and isolation devices for buildings and bridges, were implemented within the MANSIDE project Dolce et al. [2]. A smart isolator combined by a laminated rubber bearing with a SMA device was proposed for bridge protection Wilde et al. [3]. Novel SMA-based devices were also present by Li et al. [4], Zhu and Zhang [5,6], Song et al. [7], McCormick et al. [8], etc., on which experiments, numerical models and applications were investigated but most of them were still in laboratory stage. 
In the present paper, an axial-type SMA damper is developed for seismic performance upgrading of steel structures, and modeled on the basis of a simple multi-linear one dimensional constitutive law of SMAs. A seismic performance study of steel frame bridge piers with the SMA damper is performed with the help of time history analysis using several strong ground motions, and the effectiveness is verified under detailed comparisons.

\section{CONSTITUTIVE MODELS OF SMAS}

In order to simulate material behavior of SMAs numerically, microscopic methodology and macroscopic methodology are two approaches which focus on molecular level and phenomenological features of SMAs, respectively Paiva and Savi [9]. Phenomenological models are gotten more interests for their simplicity and suitability in seismic engineering application. Besides models generated from experiment results Delemont and DesRoches [10], many models were derived through different theoretical approaches. For examples, Graesser and Cozzarelli proposed a model based on one strain variable $\varepsilon$ Graesser and Cozzarelli [11], which later modified by Wilde et al. [3] and Zhu and Zhang [5]. A class of thermo-mechanical models with assumed phase transformation kinetics was firstly proposed by Tanaka [12], in which an internal variable $\xi$ was used to represent the martensite volumetric fraction. Extent researches were conducted by several authors Brinson [13]; Boyd and Lagoudas [14]; Tamai and Kitagawa [15] and Auricchio and Sacco [16].

In this study, a modified version of the constitutive model for SMA is proposed which initially developed by Motahari and Ghassemieh [17], where a kind of thermo-mechanical models was also presented.

\subsection{The Motahari and Ghassemieh Model}

A temperature-dependent multi-linear constitutive model was derived by Motahari and Ghassemieh [17] to simulate the behavior of SMAs, which originated from the special expression of Gibbs free energy of a material undergoing a solid-solid phase transformation shown below:

$G(\sigma, \xi, T)=-\frac{1}{2 \rho} \frac{\sigma^{2}}{E}-\frac{1}{\rho} \sigma\left[\alpha\left(T-T_{0}\right)+\xi \varepsilon_{L}\right]+c\left[\left(T-T_{0}\right)-T \ln \frac{T}{T_{0}}\right]-s_{0} T+u_{0}$

where $G$ represents the Gibbs free energy which is dependent on three variables, i.e., the axial stress $\sigma$, the martensite fraction $\xi$ and the working temperature $T ; s_{0}$ and $u_{0}$ are specific entropy and specific internal energy at the reference state of SMAs, respectively; $\rho, \alpha, T_{0}, E, \varepsilon_{L}$ and $c$ are the density, effective thermal expansion, reference temperature, elastic modulus, maximum residual strain and thermal expansion factor, respectively.

Following standard thermodynamics formulations, the stress expression can be derived from Eq. 1:

$$
\sigma=E \varepsilon=E(\xi)\left(-\frac{\partial G}{\partial \sigma}\right)=E(\xi)\left[\varepsilon-c\left(T-T_{0}\right)-\varepsilon_{L} \xi\right]
$$

In Eq. 2, the elastic modulus of SMAs in the transformation process is a function of the martensite fraction $\xi$, and expressed by the following Eq. 3 in the Motahari and Ghassemieh model:

$E(\xi)=E_{A}+\xi\left(E_{M}-E_{A}\right)$ 
here, $E(\xi)$ is the elastic modulus of SMAs with the martensite fraction $\xi, E_{A}$ and $E_{M}$ are SMA elastic modules in the austenite state and martensite state, respectively.

Adoption of linearization assumption between transformation stresses and strains in the isothermal process (i.e., $T=T_{0}$ ) leads to such a relation by using Eqs. 2 and 3:

$E(\xi) \varepsilon=\left(E_{A}+\xi\left(E_{M}-E_{A}\right)\right)\left[\varepsilon-\varepsilon_{L} \xi\right]=a \varepsilon+b$

here, $a$ and $b$ are two undetermined coefficients.

Considering material properties of SMA, the multi-linear constitutive model is illustrated in Figure 1(a) in which the four transformation stresses, i.e., $\sigma_{M S}, \sigma_{M F}, \sigma_{A S}$ and $\sigma_{A F}$, are determined by material constants $C_{A}, C_{M}$, transformation temperatures $T_{M S}, T_{M F}, T_{A S}, T_{A F}$ and the reference temperature $T_{0}$. If unloading occurs before completion of forward transformation or reloading occurs before completion of reversal transformation, the inner hysteretic path is illustrated in Figure 1(b) that the forward transformation takes place when the stress reaches to $\sigma_{M S}$ and the reversal transformation takes place when the stress reaches to $\sigma_{A S}$ in the inner loop.

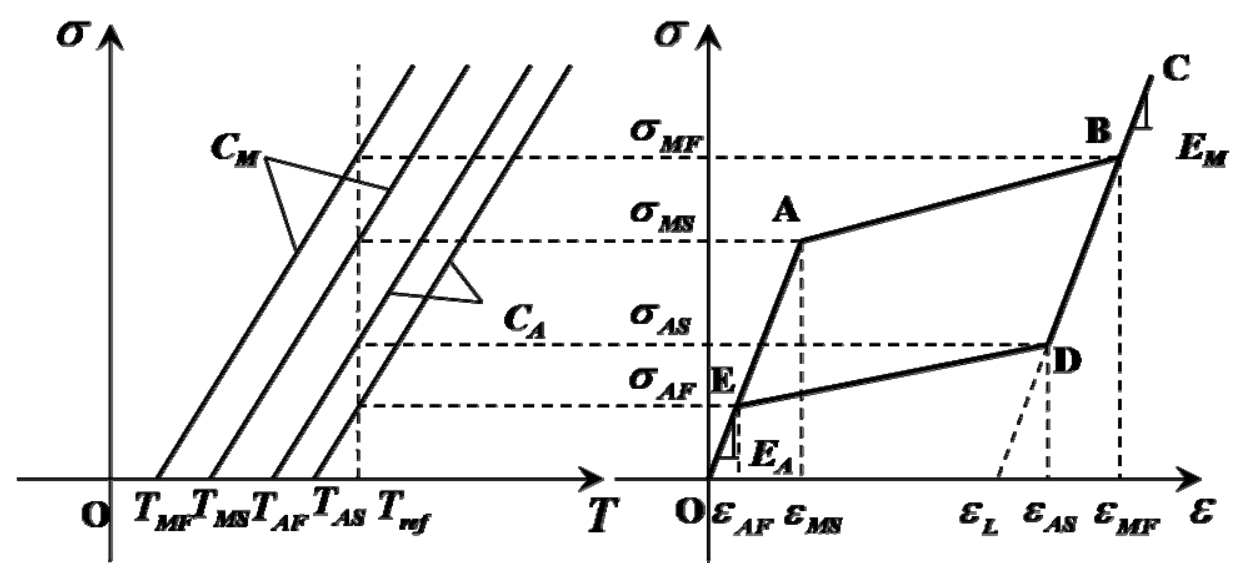

(a) Bone curve of the Motahari and Ghassemieh model

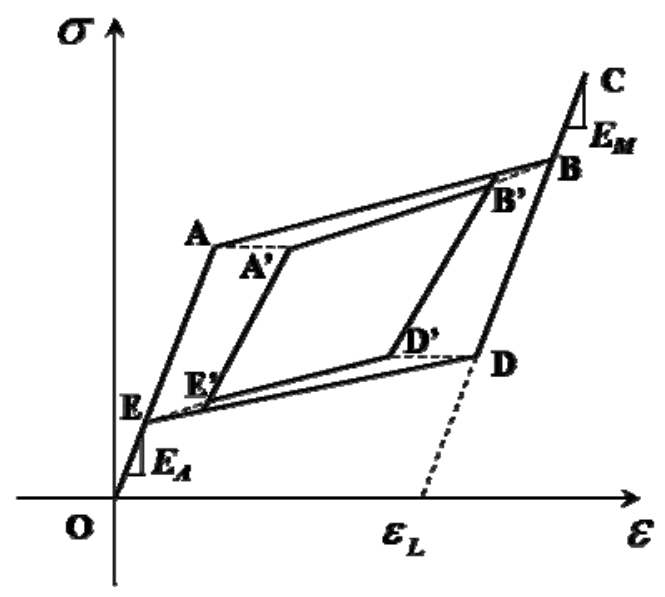

(b) Inner hysteretic loop adopted in the Motahari and Ghassemieh model

Figure 1. The Motahari and Ghassemieh Model for SMAs (Motahari and Ghassemieh [17]) 


\subsection{Modifications to the M.-G. Model}

In this study, a constitutive model for SMAs is proposed by modifying the Motahari and Ghassemieh model (i.e., the M.-G. model) to make it more applicable for engineering applications.

First, the modified model omits the relations between temperature and transformation stress. As we know, stress variation in SMAs during phase transformation precess is temperature dependent and strain rate dependent. However in such a simplified multi-linear model, the issue of considering the effect of temperature or strain rate is turned to determine the transformation stresses of SMAs during iso-thermal or adiabatic process. As shown in the left part of Figure 1(a), it is one of the effective methods to determine transformation stresses relation to temperature as origninally developed by Brinson [13]. In authors' opinion, the key part of the constitutive model in Figure 1(a) in its right part can be extracted and the transformation stresses can be determined either by the thermo-stress coupling relations in the M.-G. model or by other approaches such as experimental tests, data from material suppliers and other researchers' methods mentioned in section 1.

Next, the relation of the elastic modulus in Eq. 3 represents an upper bound for all kinds of elastic modules summarized by Auricchio, but experimental evidence shows that the assumption is quite unrealistic (Auricchio and Sacco [16]). For this reason, the equivalent modulus is adopted in Reuss scheme as follows:

$\frac{1}{E}=\frac{(1-\xi)}{E_{A}}+\frac{\xi}{E_{M}}$

Replacing Eq. 3 with Eq. 5, and substituting it into Eq. 4, the varied martensite fraction $\xi$ in the forward transformation process and the reversal transformation process can be explicitly expressed:

$\xi=\frac{E_{A} E_{M} \varepsilon-(a \varepsilon+b) E_{M}}{(a \varepsilon+b)\left(E_{A}-E_{M}\right)-E_{A} E_{M} \varepsilon_{L}}$

The proposed constitutive model can be easily illustrated in Figure 2. As shown in Figure 2(a), the bone curve of the multi-linear constitutive model is plotted when SMAs are assumed in the austenite state at the reference temperature, in which four transformation stresses, i.e., $\sigma_{M S}, \sigma_{M F}, \sigma_{A S}$ and $\sigma_{A F}$ are known and the elastic modules in the austenite state and martensite state are $E_{A}$ and $E_{M}$, respectively. The controlled transformation strains can be easily obtained as follows:

$\varepsilon_{M S}=\frac{\sigma_{M S}}{E_{A}} \quad ; \quad \varepsilon_{M F}=\frac{\sigma_{M F}}{E_{M}}+\varepsilon_{L} \quad ; \quad \varepsilon_{A S}=\frac{\sigma_{A S}}{E_{M}}+\varepsilon_{L} ; \quad \varepsilon_{A F}=\frac{\sigma_{A F}}{E_{A}}$

and then the undetermined coefficients $a$ and $b$ can be calculated from the known start transformation point and the finish transformation point.

Shown in Figure 2(b) is the model to solve detwinning process of SMAs in the martensite state, where the start and finish critical stresses are named $\sigma_{M S C R}, \sigma_{M F C R}$, and both the initial stiffness and stiffness after detwinning are taken as the same as $E_{M}$.

Different from the M.-G. model, a modified inner hysteretic strategy called diagonal rule is proposed as shown in Figure 2(c). Generally in the isothermal process, four transformation stresses, i.e., $\sigma_{M S}, \sigma_{M F}, \sigma_{A S}$ and $\sigma_{A F}$, obey the inequalities, $\sigma_{A F} \leq \sigma_{A S} \leq \sigma_{M S} \leq \sigma_{M F}$ (Auricchio and Sacco [16]). But in high frequency earthquake loadings, transformation temperatures and stresses in SMAs rise because the SMAs don't have sufficient time to dissipate heat. Due to the rate-dependent 
characteristic of SMAs, if the transformation stress $\sigma_{A S}$ is greater than $\sigma_{M S}$, the inner loop suggested in the M.-G. model would get misleading results. The diagonal rule defines the diagonal line between $\sigma_{M S}$ and $\sigma_{A S}$ as a reference line for the phase transformation start point in the inner loop. If unloading occurs before completion of forward transformation, the loading path with a slope of $E(\xi)$ at the unloading point B' descends from B' to $\mathrm{D}^{\prime}$ on the diagonal line, and then points to A (a point corresponding to $\sigma_{A F}$ ) which imitates the inner reversal transformation process. This rule is the same in the reloading process before completion of reversal transformation.

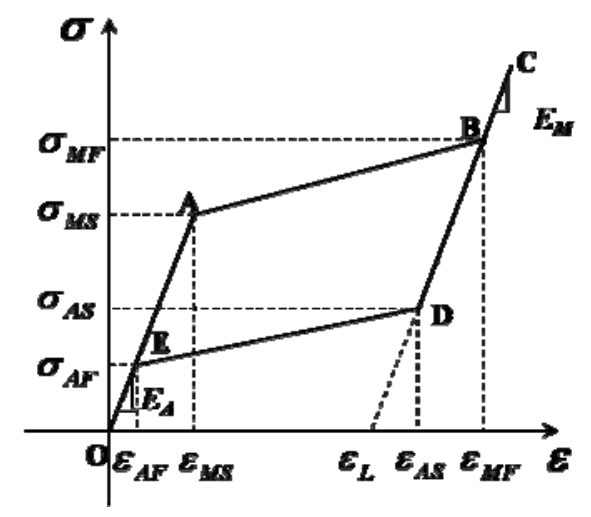

(a) Constitutive model of SMA transformation process between austenite and martensite states

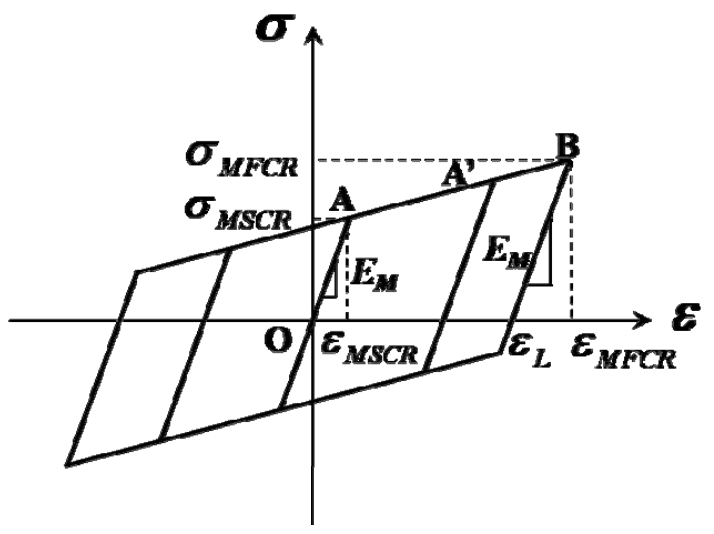

(b) Constitutive model of martensite SMA detwinning process

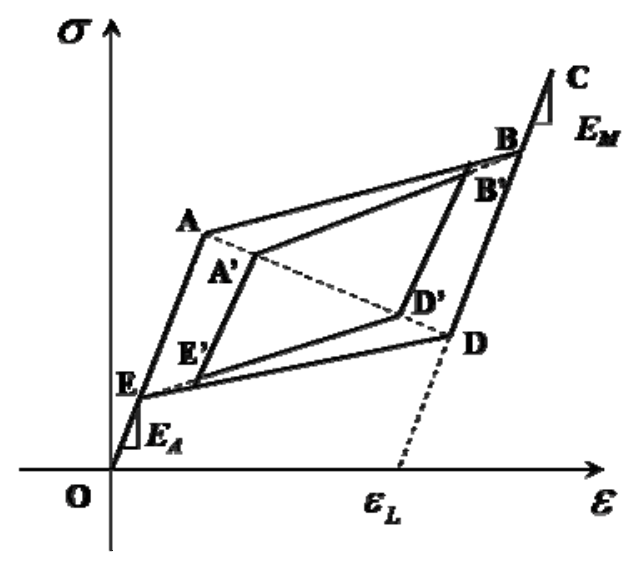

(c) Diagonal rule assumption of inner hysteretic loop

Figure 2. Modified Motahari and Ghassemieh Model for SMAs 


\section{CONSTRUCTING AND MODELING OF AXIAL-TYPE SMA DAMPER}

The axial-type SMA damper considered is shown in Figure 3(a), in which two blocks (i.e., Part A and Part B) made of steel can slide past each other, and two sets of austenite wire systems and one martensite sheet are kernel material in the damper. Lubricating material is placed at the contact interface of Part A and Part B to reduce friction. The whole SMA damper can be distinctly divided into two groups, i.e., recentering group and energy dissipation group. The recentering group consists of the two sets of austenite wires $\mathrm{A}$ and $\mathrm{B}$, which are in tension only and react in reverse directions because the austenite wires A and B have excellent superelastic ability with relative small hysteretic loop, as shown in Figure 3(b)-(1) and Figure 3(b)-(2). And the energy dissipation group is made up of the martensite sheet that is restrained so that it can afford tension and compression without undergoing buckling and its good energy dissipation ability is as shown in Figure 3(b)-(3).

The working principle of the SMA damper is described here. While the damper is in tension, Austenite Wire B is in action like Figure 3(b)-(1) and Austenite Wire A doesn't work at this moment; while the damper is in compression, Austenite Wire A is in action like Figure 3(b)-(2) and Austenite Wire B doesn't work; whether in tension or in compression, the restrained Martensite Sheet is always in action with the same amplitude like Figure 3(b)-(3). Combined the three curves together as Figure 3(b)-(4), considering fraction distributions between austenite parts and martensite part, the corresponding analytical model of the damper is constructed shown as Figure 3(b)-(5). The discontinuous points A-G in Figure 3(b)-(5) are the martensite forward transformation start point A, austenite forward transformation start point $\mathrm{B}$, martensite forward transformation finish point $\mathrm{C}$, austenite forward transformation finish point $\mathrm{D}$, austenite reversal transformation start point $\mathrm{E}$, martensite reversal transformation start point $\mathrm{F}$, austenite reversal transformation finish point $\mathrm{G}$, respectively. It is noted that the point $\mathrm{A}$ is defined as the design stress $\sigma_{d}$.

Like SMA dampers developed by Dolce et al. [2] and Zhu and Zhang [6] mentioned above, two groups, i.e., recentering group and energy dissipation group, are designed in the axial-type SMA damper. Corresponding to a pair of pre-tensioned SMA wire systems in the damper by Dolce et al. and a friction sliding surface design in the damper by Zhu and Zhang, the restrained martensite sheet is the energy dissipation group in the proposed damper of this study. Moreover, two sets of austenite SMA wire systems are set as recentering group that is similar to both the dampers. The damper by Zhu and Zhang [6] is improved from the damper by Zhu and Zhang [5] that a friction design is added to increase energy dissipation. Compared to the damper by Dolce et al., a restrained marteniste sheet instead of pretensioned wire systems is adopted in the damper to dissipate energy. If no pretension is applied in the damper by Dolce et al., the energy dissipation ability shown in Figure 3(c) is lower than that in the axial-type damper as shown in Figure 3(b)-(3). However, more than 3\% prestrain is a large load for support structures in the damper by Dolce et al. especially for bridge engineering.

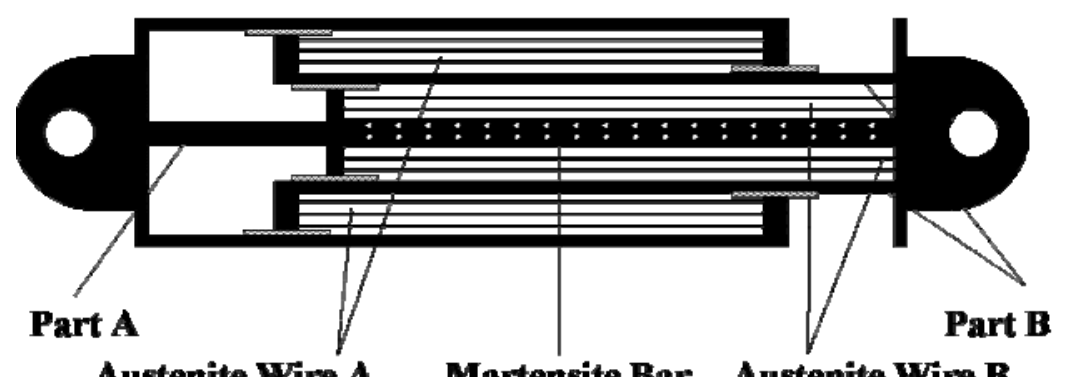

Austenite Wire A Martensite Bar Austenite Wire B

Labricating material

(a) SMA damper prototype 


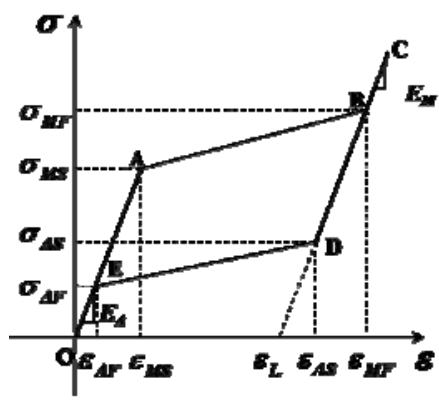

(b)-(1) Austenite Wire B

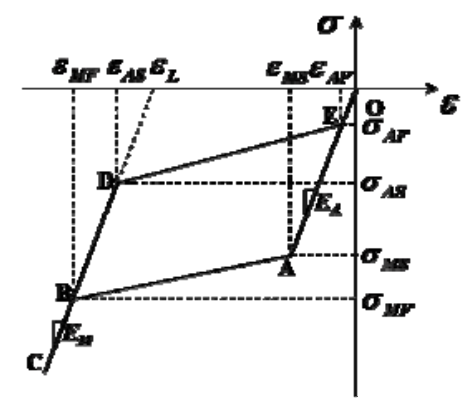

(b)-(2) Austenite Wire A

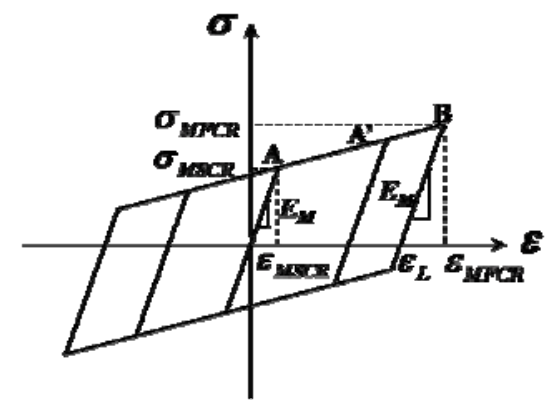

(b)-(3) Martensite Sheet

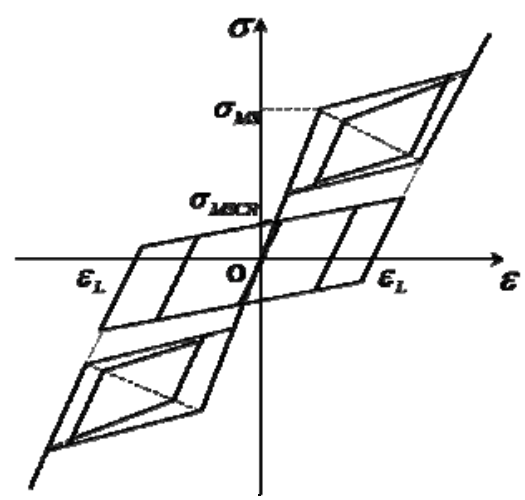

(b)-(4) Combined model of the three sets of SMA

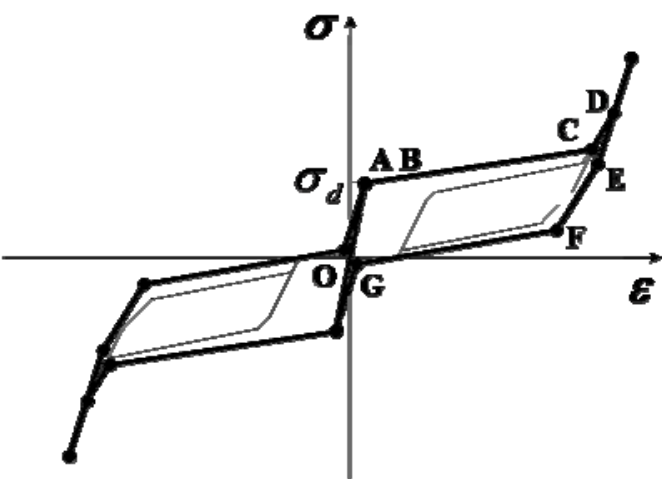

(b)-(5) Constitutive law of the SMA damper

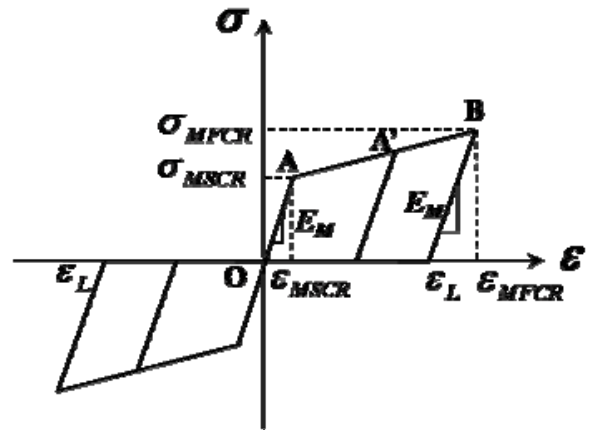

(c) Constitutive law of energy dissipation group in Dolce's damper

Figure 3. Prototype and Stress-strain Relationship of SMA Damper

\section{DESIGN AND MODELING OF SMA DAMPING DEVICES IN STEEL FRAME STRUCTURES}

A benchmark frame FA is a $12 \times 12 \mathrm{~m}$ square-shaped plane frame as shown in Figure 4 . The main frame is made of SM490 steel grade and details of the bare frame and BRB damped frame can be found in a previous study by Chen et al. [18]. The SMA damping device consists of two SMA dampers and two steel brace components, in which material constants of SMA given in the paper by Motahari and Ghasemieh [17] are employed as listed in Table 1. Steel brace components are assumed to be rigid for simplicity. The yield shear force and top displacement of the bare main frame given in Table 2 are determined from a pushover analysis. 


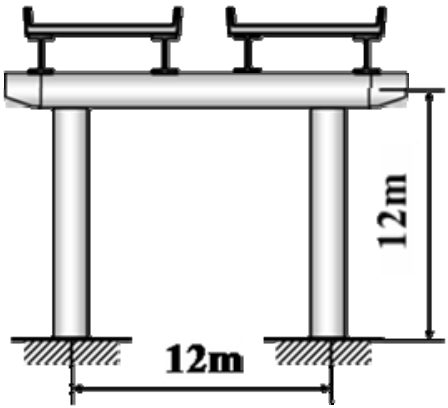

(a) Bare frame bridge pier
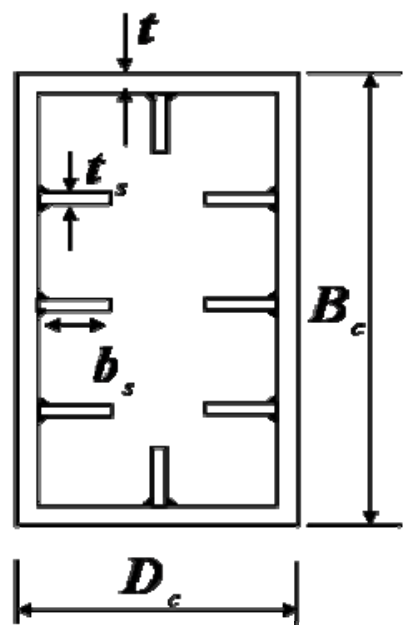

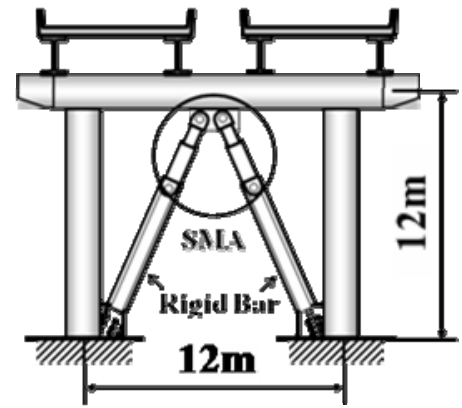

(b) Frame with SMA damper

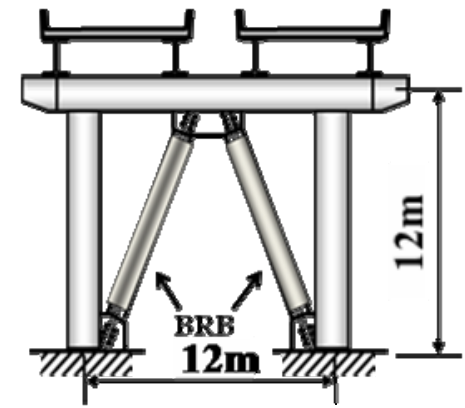

(c) Frame with equivalent BRB

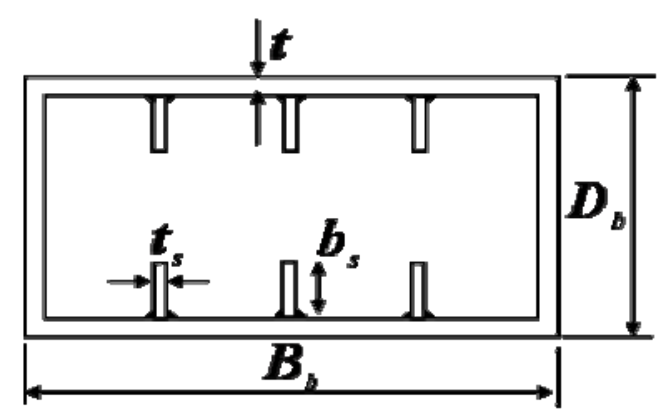

(d) Sections of frame girders and piers

Figure 4. Benchmark Frame Bridge Pier

Table 1. SMA Material Constants (Motahari and Ghassemieh [17])

\begin{tabular}{|c|c|c|c|c|}
\hline$E_{A}(\mathrm{GPa})$ & $E_{M}(\mathrm{GPa})$ & $\varepsilon_{L}$ & $T\left({ }^{\circ} \mathrm{C}\right)$ & $\sigma_{M S C R}(\mathrm{MPa})$ \\
\hline 70 & 30 & 0.05 & 40 & 100 \\
\hline$\sigma_{M S}(\mathrm{MPa})$ & $\sigma_{M F}(\mathrm{MPa})$ & $\sigma_{A S}(\mathrm{MPa})$ & $\sigma_{A F}(\mathrm{MPa})$ & $\sigma_{M F C R}(\mathrm{MPa})$ \\
\hline 235 & 325 & 210 & 100 & 170 \\
\hline
\end{tabular}

Table 2. Basic Information of the Bare Frame

\begin{tabular}{|c|c|c|c|}
\hline Name & $M(\mathrm{~kg})$ & $V_{y}(\mathrm{kN})$ & $\delta_{y, t o p}(\mathrm{~m})$ \\
\hline FA & 2042 & 6758 & 0.078 \\
\hline
\end{tabular}

Four strong ground motions are considered in the analysis, three of which are recommended in the JRA code [19], i.e., JRT-EW-M, JRT-NS-M and FUKIAI-M, and the other is LA16 available in SAC [20].

As in a previous study of controlled structures Ye and Ouyang [21], three parameters, i.e., the strength ratio $\alpha_{F}$, the stiffness ratio $\alpha_{K}$ and the displacement ratio $\alpha_{\delta}$, were proposed as design governing parameters shown below: 
$\alpha_{F}=\frac{F_{y, d}}{F_{y, f}} \quad \alpha_{k}=\frac{K_{y, d}}{K_{y, f}} \quad \alpha_{\delta}=\frac{\delta_{y, d}}{\delta_{y, f}}$

here, $F_{y, d}, K_{y, d}$ and $\delta_{y, d}$ are yield strength, elastic stiffness and yield displacement of the damping device, respectively, while $F_{y, f}, K_{y, f}$ and $\delta_{y, f}$ are those of the main structure.

Geometric parameters and basic properties of the SMA damping device are illustrated in Figure 5, where $(E A)_{S M A}$ and $l_{S M A}$ are stiffness and length of the SMA damper, respectively, $(E A)_{b}$ and $l_{b}$ are stiffness and length of the steel brace, respectively, $F_{S M A}, K_{S M A}$ and $\delta_{S M A}$ are lateral yield force, elastic stiffness and displacement of the SMA damping device, respectively. $\alpha_{L}$ and $\beta_{L}$ are taken as two scale factors on the length ratio and stiffness ratio between the steel brace component and SMA damper listed below:

$\alpha_{L}=l_{b} / l_{S M A}$

$\beta_{L}=(E A)_{b} /(E A)_{S M A}$

Moreover, $l$ is the whole length of the damping device.

$l=l_{S M A}+l_{b}$

Relationships between $F_{S M A}, K_{S M A}$ and $\delta_{S M A}$ are expressed by:

$F_{S M A}=K_{S M A} \delta_{S M A}$

and $K_{S M A}$ and $\delta_{S M A}$ can be obtained as follow:

$K_{S M A}=A_{S M A} \cdot \frac{1}{C_{1}} \frac{E_{S M A} L^{2}}{l^{3}}$

$\delta_{S M A}=\frac{\sigma_{S M A}}{E_{S M A}} \frac{l^{2}}{L} C_{1}$

in which,

$C_{1}=\frac{2}{\left(1+\alpha_{L}\right)}\left(1+\frac{\alpha_{L}}{\beta_{L}}\right)$

As a result, Eq. 12 can be rewritten as:

$F_{S M A}=\sigma_{S M A} A_{S M A} \frac{L}{l}$

In particular, $\alpha_{L}=0$ means that the damper is designed by full SMA component and $\beta_{L}=\infty$ means that the stiffness of the steel brace is assumed to be rigid. 


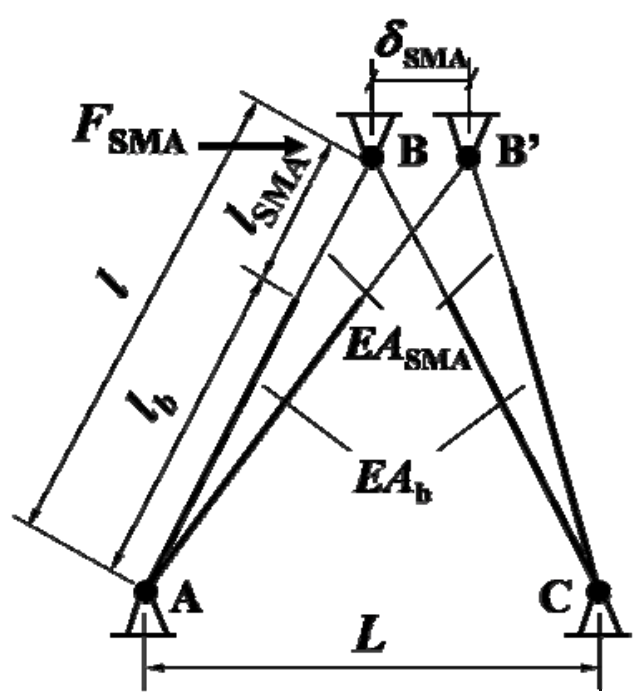

Figure 5. Schematic diagram for SMA damping device

\section{RESULTS AND COMMENTS}

In order to investigate the upgrading effectiveness of the seismic performance of frames with SMA damping devices, performance parameters to be investigated include:

1) maximum top displacement, $\delta_{\max }$;

2) residual top displacement, $\delta_{\text {res }}$;

3) maximum base shear, $V_{\max }$;

4) normalized axial strain of SMA dampers, $\varepsilon_{\max } / \varepsilon_{y) S M A}$; and

5) normalized average compressive strain at the base of the pier, $\varepsilon_{a, \max } / \varepsilon_{y) \text { Steel }}$.

These five performance parameters are evaluated under considerations of four influence factors listed as follows:

1) strength ratio, $\alpha_{F}$;

2) martensite fraction of SMA dampers, $\xi$;

3) length ratio, $\alpha_{L}$; and

4) ground motion.

\subsection{Effects of Strength Ratio $\alpha_{F}$}

Only JRT-EW-M accelerogram is used for the time-history analysis presented in this subsection. For comparison, equivalent frames with BRB dampers are designed with the same strength ratio $\alpha_{F}$ and stiffness ratio $\alpha_{K}$ as frames with austenite SMA damping devices, and the basic information of SMA models and BRB models are shown in Table 3. The response results are illustrated in Figure 6 and maximum seismic responses are listed in Table 4.

Shown in Figure 6(a) are the time history responses of the top displacement for the SMA and BRB models together with the bare frame. Compared to the bare frame, it can be seen that the displacement demands are greatly reduced in both the damped models. With the same strength ratio, comparisons bewteen the SMA and BRB models indicate that the maximum top displacement in the SMA models is a little larger, but the residual top displacement is far less than those in the BRB models. Stress-strain responses of the SMA and BRB dampers with the same $\alpha_{F}$ are also investigated as shown in Figure 6(b), the hysteretic loops of SMAs are shallower than those of 
BRBs. Relationships between the total base shear and top displacement of damped frames are shown in Figure 6(c) that the maximum base shear and maximum top displacement in the SMA models are larger than those in the BRB models.

Table 4 represents normalized maximum responses obtained from the time-history analysis. Compared to the bare frame, significant reductions can be seen in nearly all the performance parameters except for the maximum base shear. From comparisons between the SMA and BRB models with the same $\alpha_{F}$ and $\alpha_{K}$, it is found that the efficiency of the BRB models is better than the SMA models except for the ability of re-centering. For example, in the case of $\alpha_{F}=1.0$, the residual top displacement in the SMA models reaches to $0.002 \delta_{y}$ while $0.151 \delta_{y}$ in the BRB models, and the maximum average strain at the base of the pier in the BRB models is nearly $0.9 \varepsilon_{y}$, while $1.4 \varepsilon_{y}$ in the SMA models which is still less than $2.0 \varepsilon_{y}$, which is required for the performance level 2 as in Usami et al. [22].

The facts revealed in Figure 6 and Table 4 suggest that excellent superelastic recovery mechanism restrains full development of energy dissipation ability in austenite SMA dampers, so in generally the energy dissipating ability of the BRB dampers is better than the SMA's, but the seismic demands of frames with SMA damping devices can still be effectively controlled in light damage (i.e., $\varepsilon_{a, \max } \leq 2.0 \varepsilon_{y}$ ). Moreover, the re-centering ability in the SMA models is far better than those in the BRB models so that it is useful for reducing permanent deformation in structures under strong earthquakes.

Table 3. Basic Information of BRB and SMA Models

\begin{tabular}{|c|c|c|c|c|c|}
\hline Case & $\alpha_{F}$ & $\alpha_{K}$ & $\sigma_{y}(\mathrm{MPa})$ & $A\left(\mathrm{~m}^{2}\right)$ & $\alpha_{L}$ \\
\hline B-F05 & 0.5 & 6.32 & 59.3 & 0.092 & -- \\
\hline B-F10 & 1.0 & 6.41 & 118 & 0.093 & -- \\
\hline B-F15 & 1.5 & 6.42 & 172 & 0.093 & -- \\
\hline S-F05 & 0.5 & 6.32 & 235 & 0.023 & 10.3 \\
\hline S-F10 & 1.0 & 6.41 & 235 & 0.047 & 4.69 \\
\hline S-F15 & 1.5 & 6.42 & 235 & 0.068 & 2.90 \\
\hline \multicolumn{6}{|c|}{$\begin{array}{l}\text { Note: B-F and S-F represent BRB models and SMA models } \\
\text { respectively, and numbers after F stand for the value of the } \\
\text { strength ratio } \alpha_{F} \text {. }\end{array}$} \\
\hline
\end{tabular}

Table 4. Effects of $\alpha_{F}$

\begin{tabular}{|c|c|c|c|c|c|}
\hline \multirow{2}{*}{ Case } & \multicolumn{5}{|c|}{ Time history analysis results } \\
\cline { 2 - 6 } & $\frac{\varepsilon_{a) \max }}{\varepsilon_{y}}$ & $\frac{\delta_{\max }}{\delta_{y, f}}$ & $\frac{\delta_{\text {res }}}{\delta_{y, f}}$ & $\frac{V_{b, \max }}{F_{y, f}}$ & $\left.\frac{\varepsilon_{\max }}{\varepsilon_{y}}\right)_{\text {SMA }}$ \\
\hline Bare & 20.4 & 3.33 & 0.981 & 1.19 & -- \\
\hline B-F05 & 2.01 & 1.69 & 0.138 & 1.10 & 14.5 \\
\hline S-F05 & 3.77 & 2.15 & 0.023 & 1.65 & 18.8 \\
\hline B-F10 & 0.889 & 0.995 & 0.151 & 1.28 & 4.36 \\
\hline S-F10 & 1.43 & 1.91 & 0.002 & 1.70 & 8.38 \\
\hline B-F15 & 0.653 & 0.945 & 0.046 & 1.57 & 2.84 \\
\hline S-F15 & 0.731 & 1.00 & 0.008 & 1.65 & 3.06 \\
\hline
\end{tabular}



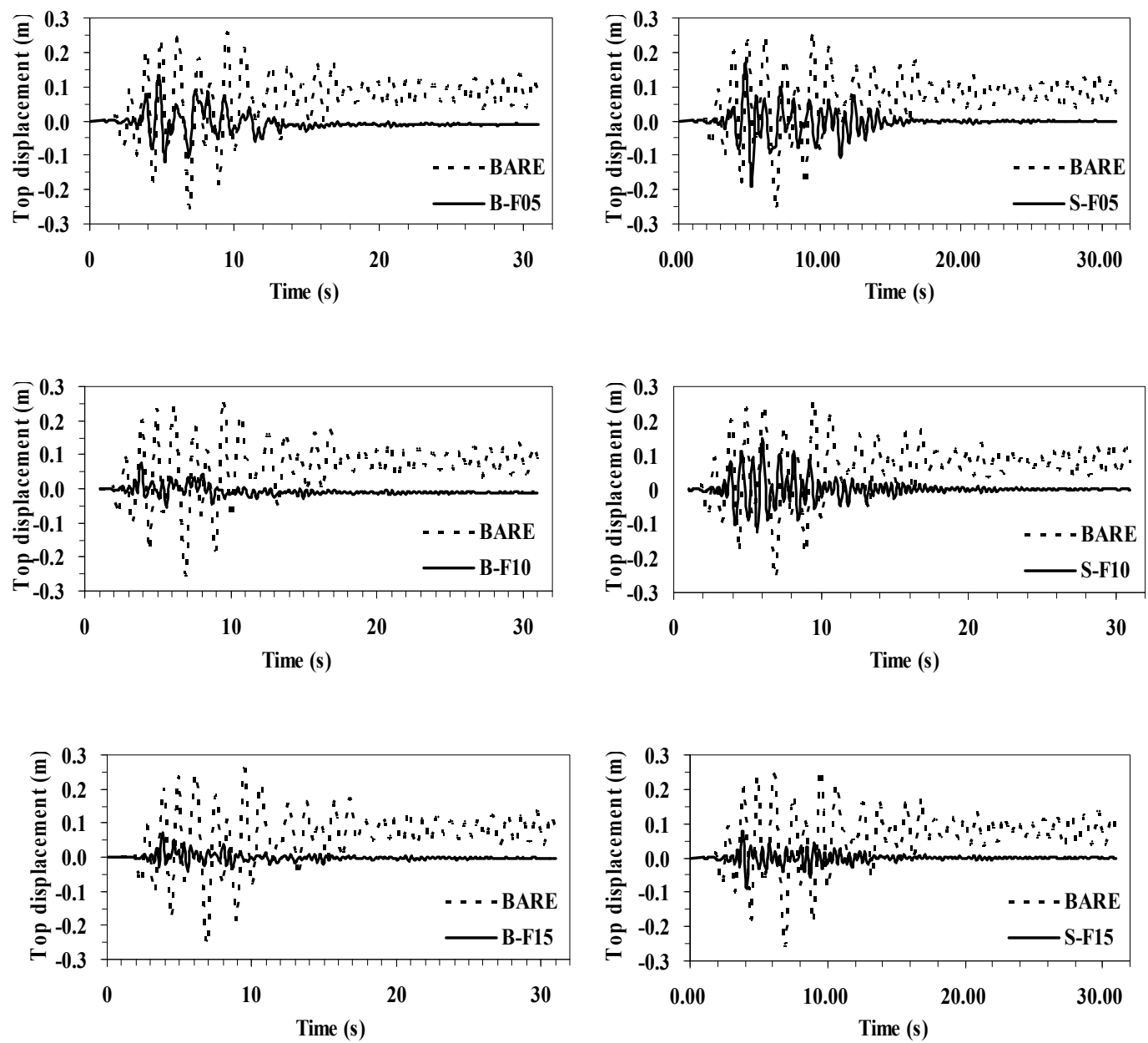

(a) Top displacement response
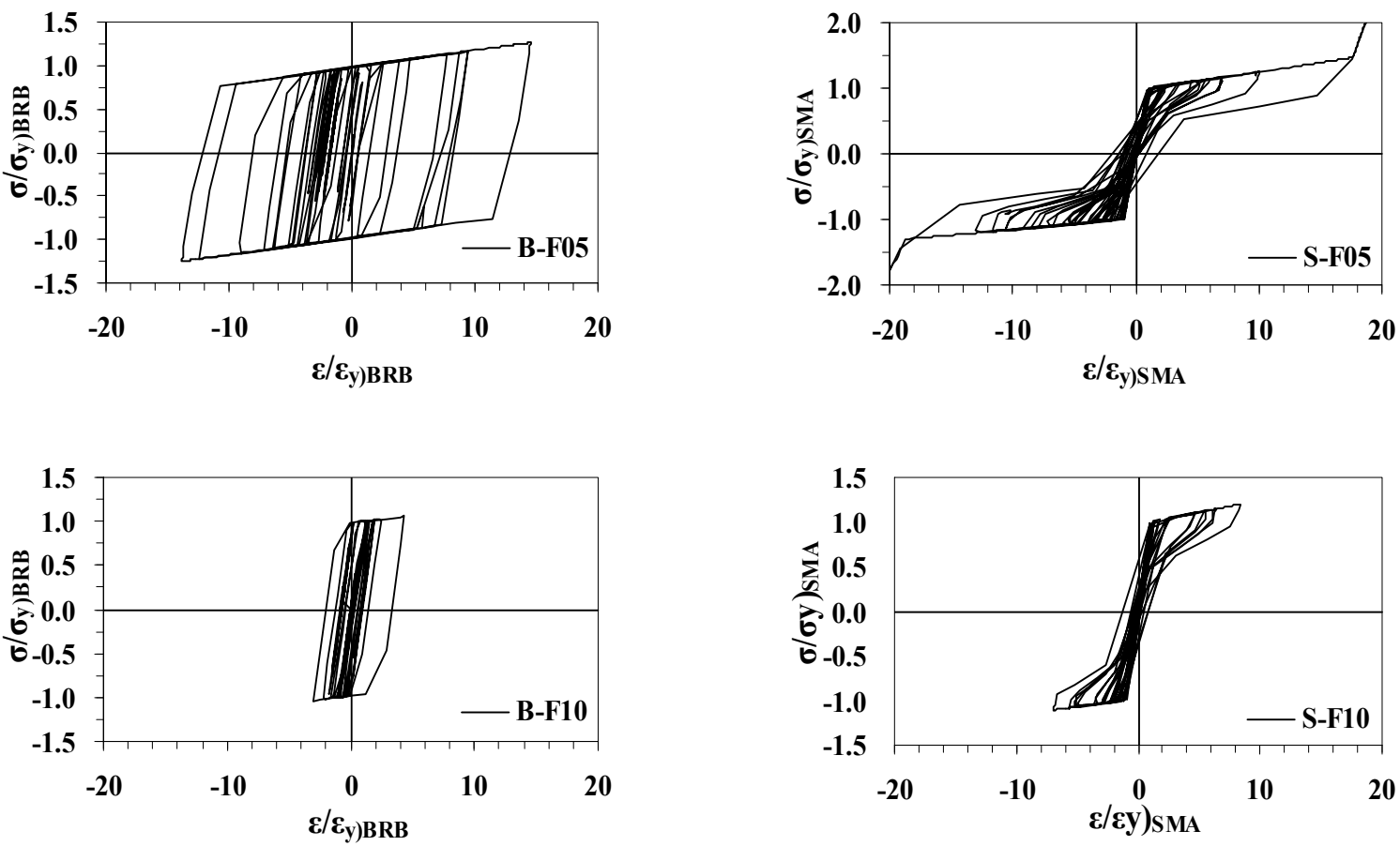

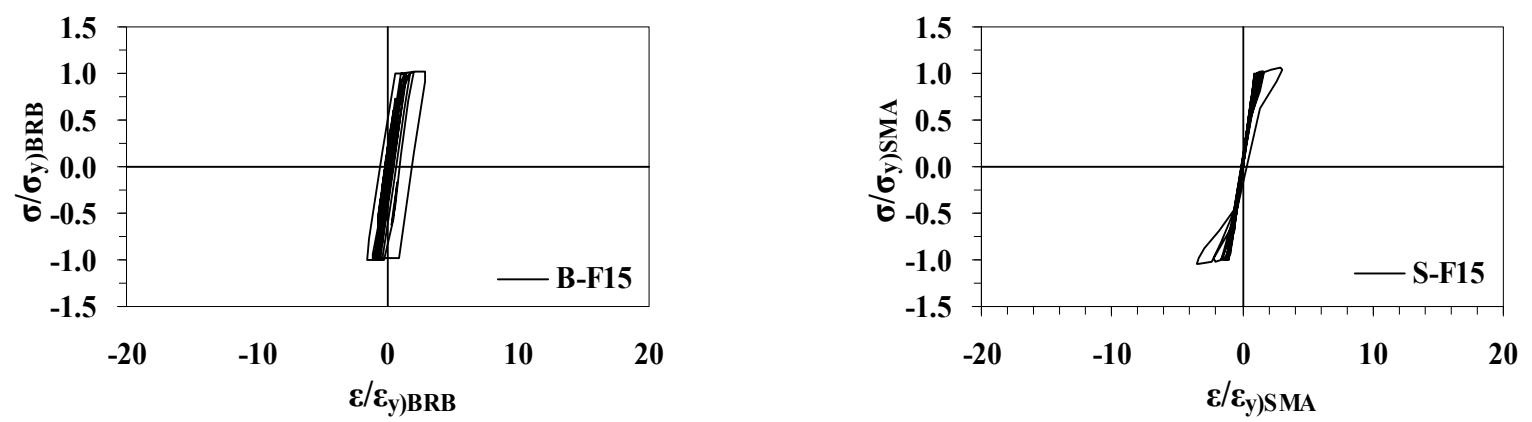

(b) Stress-strain response of dampers
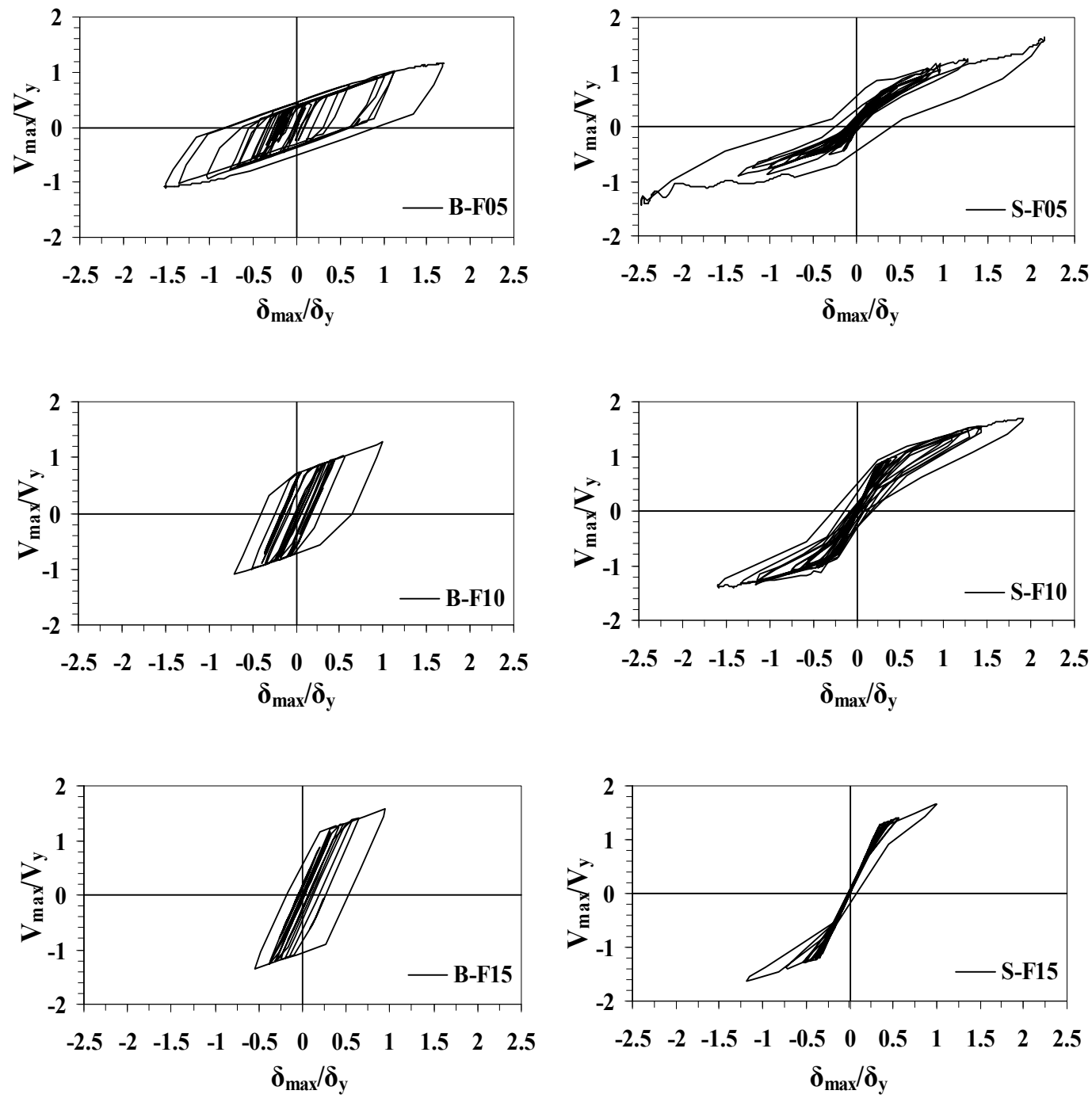

(c) Base shear-top displacement responses

Figure 6. Comparisons between the BRB and SMA Models with Different Strength Ratios $\alpha_{F}$ 


\subsection{Effects of Martensite Fraction $\xi$ in SMA Dampers}

Only JRT-EW-M accelerogram, the strength ratio $\alpha_{F}=1.0$ and the length ratio $\alpha_{L}=4.69$ are used here. Five different cases are investigated with five different martensite fractions, i.e., $0 \%, 25 \%, 50 \%$, $75 \%$ and $100 \%$, which mentioned as M00, M25, M50, M75 and M100. It is noted that the case of M00 is the same as the case S-F10. Because of different start transformation stresses in the austenite and martensite states, areas of SMA are calculated based on Eq. 16 and listed in Table 5.

Table 5. Effects of $\xi$

\begin{tabular}{|c|c|c|c|c|c|c|}
\hline \multirow{2}{*}{ Case } & \multicolumn{7}{|c|}{ Time history analysis results } \\
\cline { 2 - 7 } & $\begin{array}{c}A \\
\left(\mathrm{~m}^{2}\right)\end{array}$ & $\frac{\varepsilon_{a) \max }}{\varepsilon_{y}}$ & $\frac{\delta_{\max }}{\delta_{y, f}}$ & $\frac{\delta_{r e s}}{\delta_{y, f}}$ & $\frac{V_{b, \max }}{F_{y, f}}$ & $\left.\frac{\varepsilon_{\max }}{\varepsilon_{y}}\right)_{S M A}$ \\
\hline M00 & 0.0465 & 1.43 & 1.91 & 0.002 & 1.70 & 8.38 \\
\hline M25 & 0.0543 & 1.40 & 1.68 & 0.008 & 1.64 & 7.48 \\
\hline M50 & 0.0653 & 1.35 & 1.29 & 0.028 & 1.52 & 5.77 \\
\hline M75 & 0.0817 & 0.856 & 0.932 & 0.040 & 1.43 & 4.26 \\
\hline M100 & 0.1093 & 0.706 & 0.829 & 0.034 & 1.40 & 4.11 \\
\hline
\end{tabular}

Shown in Figure 7(a) are the time history responses of the top displacement for the SMA models with different martensite fractions. Compared to the case of M00, it can be seen that with the increase of the martensite fraction, the residual top displacements increase and the maximum displacement demands are reduced. Shown in Figure 7(b) are the stress-strain responses of dampers, and the same tendency also appears in the relationships between the total base shear versus top displacement shown in Figure 7(c) that the hysteretic loop turns more and more stable and full as the content of martensite SMA increases.

The normalized maximum responses from the time history analysis are shown in Table 5. As we can see, investigated performances of $\delta_{\max }, V_{\max }$ and $\varepsilon_{a, \max }$ are improved with increasing content of martensite SMA, but the performance of $\delta_{\text {res }}$ decreases because of lack of super-elasticity in martensite SMAs. For example, the maximum base shear decreases from nearly $1.7 V_{y}$ in the case of M00 to below $1.4 V_{y}$ in the case of M100, while the corresponding residual top displacement increases from $0.002 \delta_{y, f}$ to $0.034 \delta_{y, f}$.

\subsection{Effects of Length Ratio $\alpha_{L}$ in Damping Devices}

Only JRT-EW-M accelerogram, the strength ratio $\alpha_{F}=1.0$ and the martensite fraction ratio $\xi=0$ are used here. Five different length ratios, i.e., 1, 2, 4, 6 and 4.69, are considered. The case of 4.69 is the same as the cases of S-F10 and M00 in the above subsections.

Under the conditions of the same SMA area and martensite fractions, from Eqs. 13 and 15, it can be found that the bigger the length ratio, the larger the stiffness of the damping device. From the normalized maximum responses shown in Table 6, it is noted that with the length ratio increasing, all investigated performances of $\delta_{\max }, V_{\max }, \varepsilon_{a, \max } / \varepsilon_{y) \text { Steel }}$ and $\delta_{\text {res }}$ are improved, and $\varepsilon_{\max } / \varepsilon_{y) S M A}$ increases rapidly mainly because the length of SMA damper is shorten with the increased length ratio. 

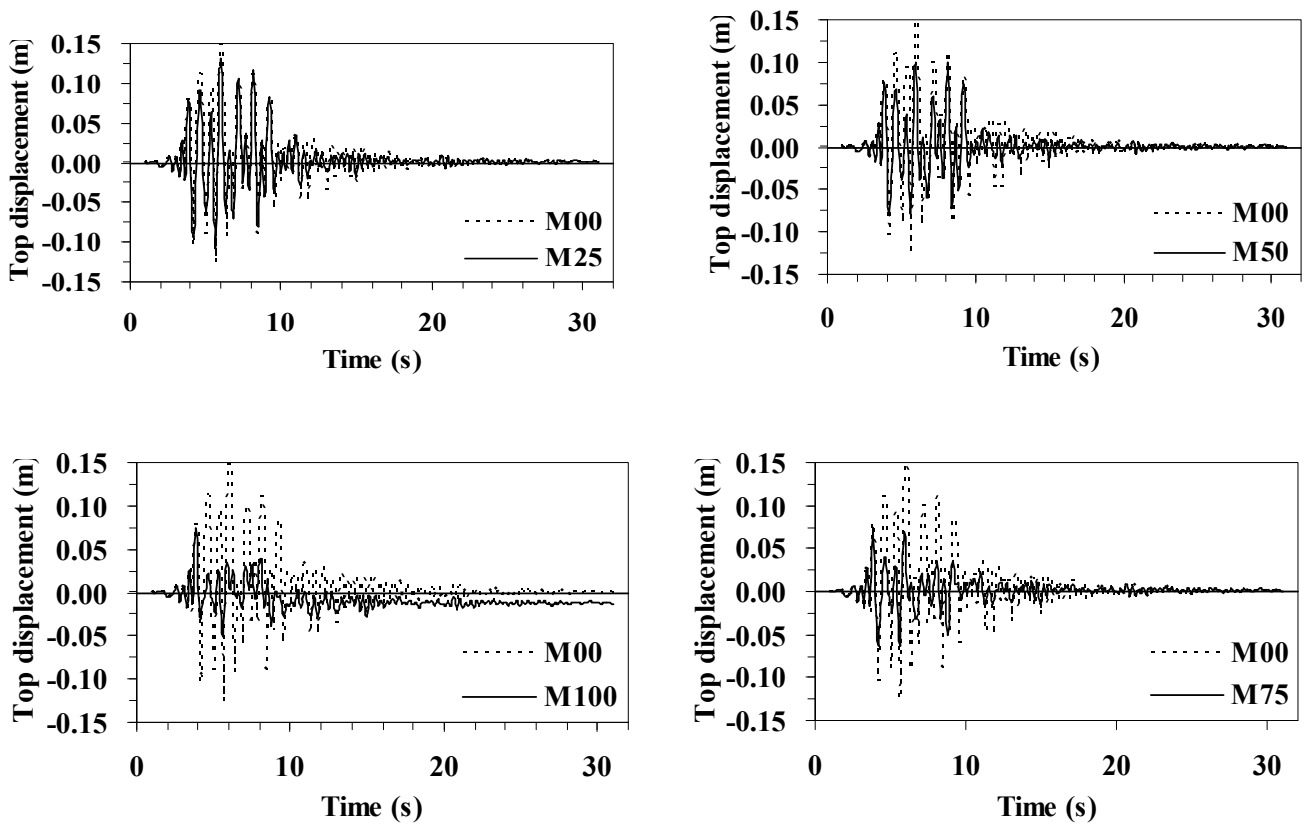

(a) Top displacement response
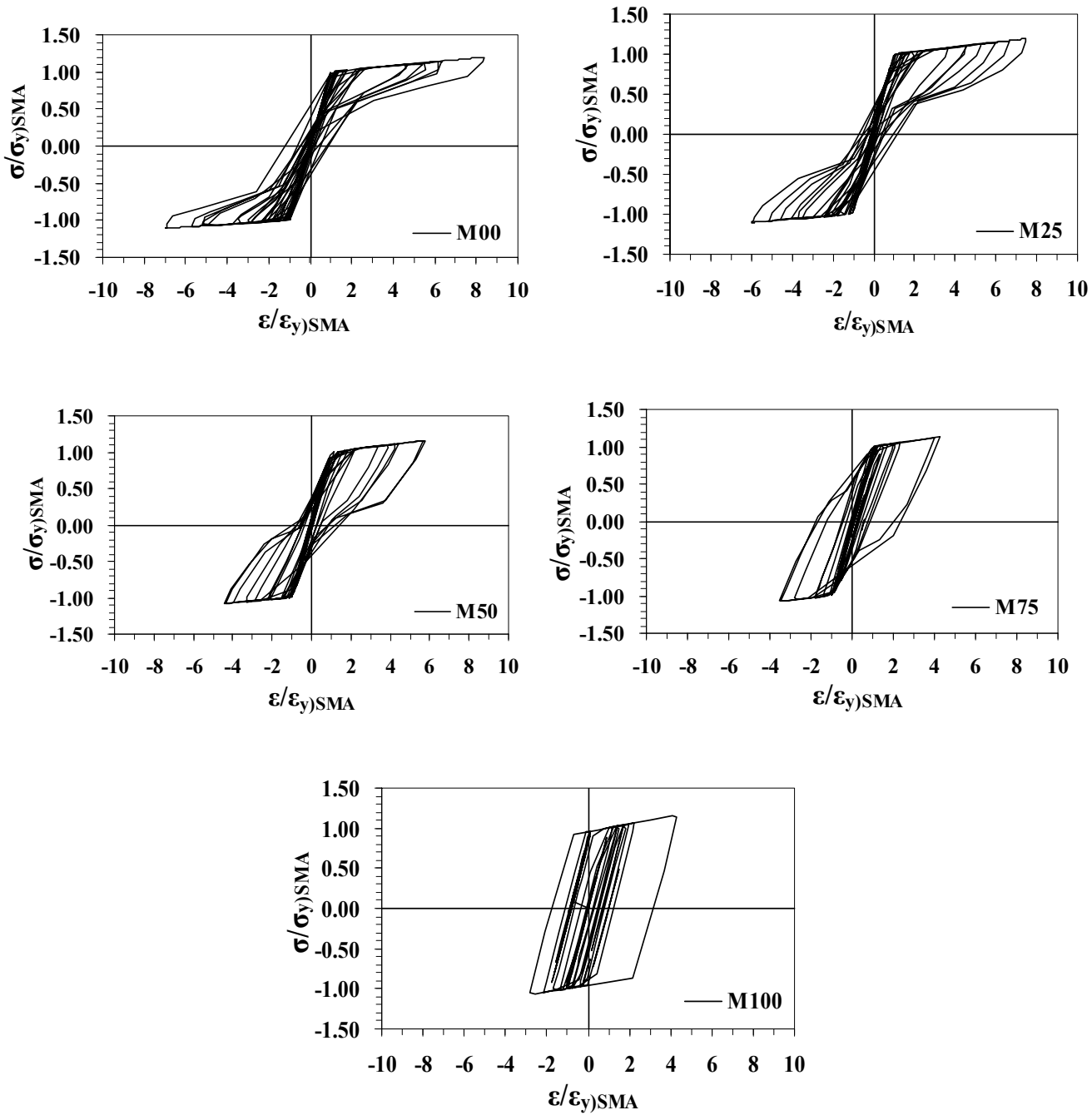

(b) Stress-strain Response of Dampers 

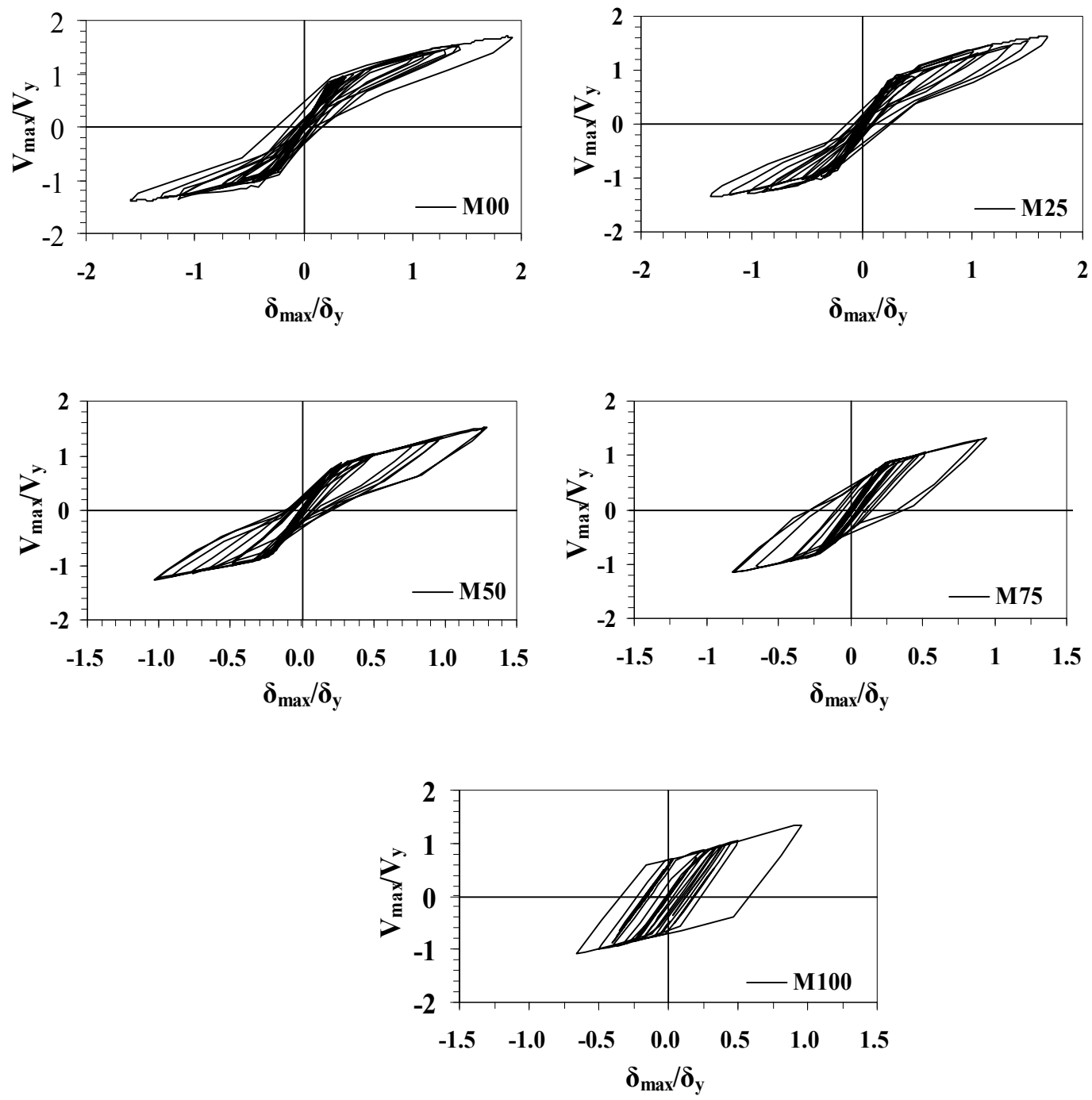

(c) Base Shear-top Displacement Responses

Figure 7. Comparisons of SMA Models with Different Martensite Fraction Ratios $\xi$

Table 6. Effects of $\alpha_{L}$

\begin{tabular}{|c|c|c|c|c|c|}
\hline \multirow{2}{*}{ Case } & \multicolumn{5}{|c|}{ Time history analysis results } \\
\cline { 2 - 6 } & $\frac{\varepsilon_{a) \max }}{\varepsilon_{y}}$ & $\frac{\delta_{\max }}{\delta_{y, f}}$ & $\frac{\delta_{r e s}}{\delta_{y, f}}$ & $\frac{V_{b, \max }}{F_{y, f}}$ & $\left.\frac{\varepsilon_{\max }}{\varepsilon_{y}}\right)_{\text {SMA }}$ \\
\hline L4.69 & 1.43 & 1.91 & 0.002 & 1.70 & 8.38 \\
\hline L1 & 1.92 & 2.05 & 0.070 & 1.57 & 3.06 \\
\hline L2 & 1.83 & 1.90 & 0.049 & 1.57 & 4.34 \\
\hline L4 & 1.51 & 1.93 & 0.013 & 1.69 & 7.39 \\
\hline L6 & 1.59 & 1.86 & 0.013 & 1.74 & 10.2 \\
\hline
\end{tabular}

\subsection{Effects of Various Strong Ground Motions}

To further investigate efficiency of dampers under various ground motions, except for aforementioned JRT-EW-M, three other ground motions JRT-NS-M, FUKIAI-M and LA16 are employed. The bare frame, frames with SMA damping devices and equivalent frames with BRB dampers under $\alpha_{F}=0.5$ are considered. 
The result comparisons are illustrated in Figure 8. Compared to the bare frame, it is clear as mentioned before that each performance demand in the damped frames has a large reduction except for the base shear force. Comparing between the SMA and BRB models, it can be found that most performance indices of the SMA models are larger than the BRB models, particularly in JRT-NS-M and FUKIAI-M cases. The residual top displacements of the SMA models are far less than those of the BRB models under the ground motions of JRT-EW-M and LA16 but almost equal under the ground motions of JRT-NS-M and FUKIAI-M. Therefore, it can be concluded that the performance of the SMA model is much more sensitive to earthquake inputs, and attentions are needed in practical design.

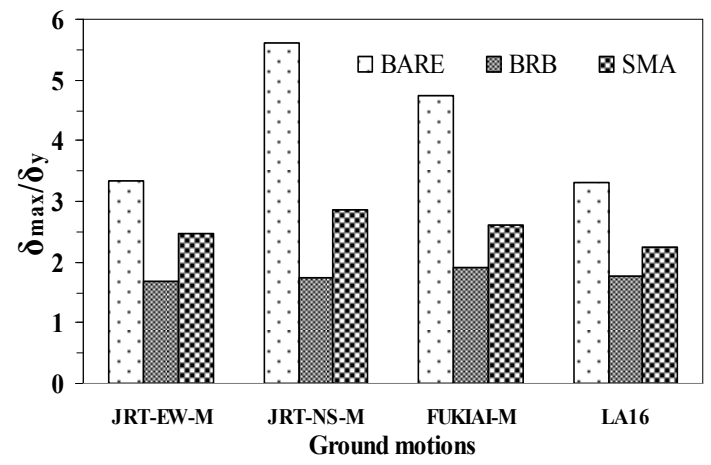

(a) Normalized max top disp.

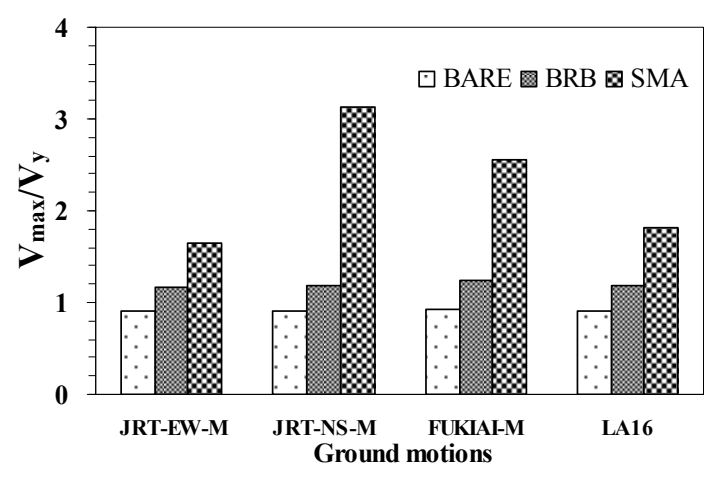

(c) Normalized max shear force

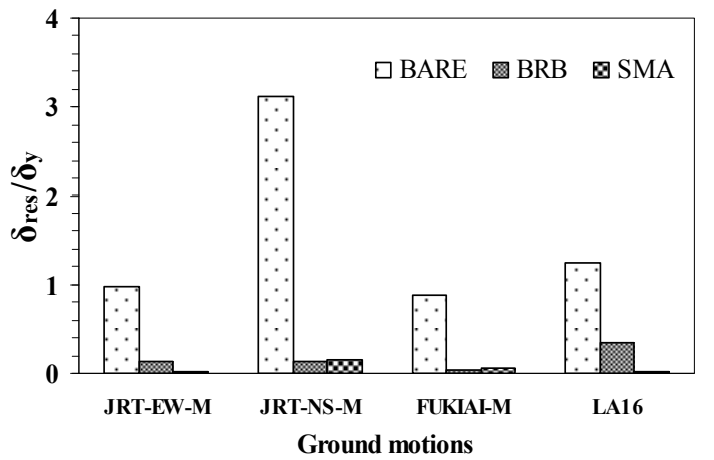

(b) Normalized residual top disp.

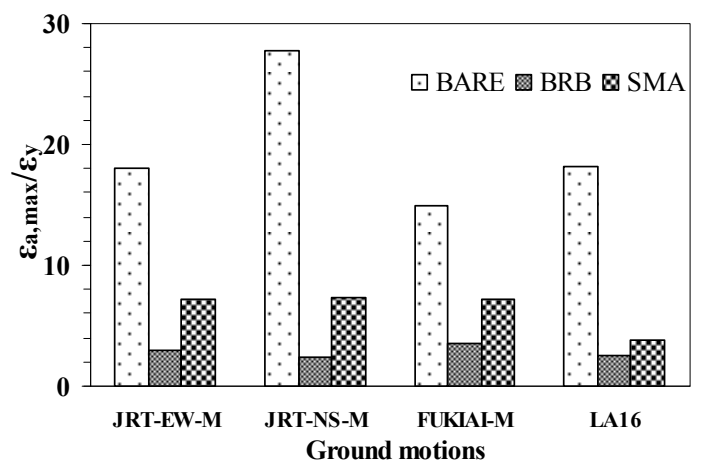

(d) Normalized average strain at piers

Figure 8. Comparison of SMA Models with Various Strong Earthquake Motions

\section{CONCLUSIONS}

This paper is dealt with applications of superelastic SMAs for seismic performance upgrading of civil engineering structures. Initially, a modified multi-linear model with diagonal rule which accounts for inner hysteretic loops is developed for SMA material. Then, an axial-type SMA damper is proposed and the corresponding modeling is presented based on the material model.

Dynamic numerical simulations have been implemented to evaluate the seismic behavior of a benchmark steel portal frame using SMA damping devices. Comparisons with the bare frame and the equivalent frame with BRB dampers are carried out and four influence factors are considered. Following conclusions can be drawn: 
1) Compared to the bare frame, use of the SMA damper is effective to improve seismic performance of the main structure.

2) If designed with the same $\alpha_{F}$ and $\alpha_{K}$, a SMA damper is superior to BRBs on re-centering ability. However, the energy dissipation ability in SMA dampers is less than in BRB dampers. Thus, selection of SMA dampers should be attractive to control the residual displacement for special structures after strong earthquake.

3) The more the martensite content include in the SMA damper, the more the re-centering ability loses and the more the energy dissipating ability has in the frame.

4) When the length ratio increases, the stiffness of the brace system increases and the energy dissipating ability increases.

5) The performance of structures with the SMA damper is sensitive to earthquake inputs, and attentions are needed in practical design.

\section{ACKNOWLEDGEMENT}

The study was supported in part by grants from the Advanced Research Center for Seismic Experiments and Computations, Meijo University, which supported by Ministry of Education, Culture, Sports, Science and Technology (MEXT), Japan.

\section{REFERENCES}

[1] Weber, F., Feltrin, G., Huth, O., "Guidelines for Structural Control”, SAMCO Final Report by Structural Engineering Research Laboratory, Swiss Federal Laboratories for Materials Testing and Research, Dübendorf, Switzerland, 2006.

[2] Dolce, M., Cardone, D. and Marnetto, R., "Implementation and Testing of Passive Control Devices Based on Shape Memory Alloys”, Earthquake Engng Struct. Dyn., 2000, Vol. 29, pp. 945-968.

[3] Wilde, K., Gardoni, P. and Fujino, Y., "Base Isolation System with Shape Memory Alloy Device for Elevated Highway Bridges", Engineering Structures, 2000, Vol. 22, pp. 222-229.

[4] Li, H., Mao, C.X., and Ou, J.P., "Experimental and Theoretical Study on Two Types of Shape Memory Alloy Devices”, Earthquake Engng Struct. Dyn., 2007, Vol. 37, pp. 407-426.

[5] Zhu, S.Y. and Zhang, Y.F., "Seismic Behavior of Self-centring Braced Frame Buildings with Reusable Hysteretic Damping Brace”, Earthquake Engng Struct. Dyn., 2007, Vol. 36, pp. 1329-1346.

[6] Zhu, S.Y. and Zhang, Y.F., "Seismic Analysis of Concentrically Braced Frame Systems with Self-Centering Friction Damping Braces", Journal of Structural Engineering, ASCE, 2008, Vol. 134, No. 1, pp. 121-131.

[7] Song, G., Ma, N., Li, H.N., "Applications of Shape Memory Alloys in Civil Structures", Engineering Structures, 2006, Vol. 28, pp. 1266-1274.

[8] McCormick, J., DesRoches, R., Fugazza, D. and Auricchio, F., "Seismic Assessment of Concentrically Braced Steel Frames with Shape Memory Alloy Braces”, Journal of Structural Engineering, ASCE, 2007, Vol. 133, No. 6, pp. 862-870.

[9] Paiva, A. and Savi, M.A., "An Overview of Constitutive Models for Shape Memory Alloys", Mathematical Problems in Engineering, 2006, pp. 1-30. 
[10] Delemont, M. and DesRoches, R., "Seismic Retrofit of Simply Supported Bridges Using Shape Memory Alloys", Engineering Structures, 2002, Vol. 24, pp. 325-332.

[11] Graesser, E.J. and Cozzarelli, F.A., "Shape-memory Alloys as New Materials for Aseismic Isolation", Journal of Engineering Mechanics, ASCE, Vol. 117, No. 11, pp. 2590-2608.

[12] Tanaka, K., "A Thermomechanical Sketch of Shape Memory Effect: One-dimensional Tensile Behavior", Materials Science Research International, 1985, Vol. 18, pp. 251-263.

[13] Brinson, L.C., "One Dimensional Constitutive Behavior of Shape Memory Alloys: Thermomechanical Derivation with Non-constant Material Functions and Redefined Martensite Internal Variable", Journal of Intelligent Material Systems and Structures, 1993, Vol. 4, pp. 229-242.

[14] Boyd, J.G. and Lagoudas, D.C., "A Thermodynamic Constitutive Model for the Shape Memory Materials. Part I: the Monolithic Shape Memory Alloys", Int. J. of Plasticity, 1996, Vol. 12, No. 6, pp. 805-842.

[15] Tamai, H. and Kitagawa, Y., "Pseudoelastic Behavior of Shape Memory Alloy Wire and its Application to Seismic Resistance Member for Building", Computational Material Science, 2002, Vol. 25, pp. 218-227.

[16] Auricchio, F. and Sacco, E., "A One-dimensional Model for Superelastic Shape-memory Alloys with Different Elastic Properties between Austenite and Martensite", Int. J. Nonlinear Mechanics, 1997, Vol. 32, No. 6, pp. 1101-1114.

[17] Motahari, S.A. and Ghassemieh, M., "Multilinear One-dimensional Shape Memory Material Model for Use in Structural Engineering Applications", Engineering Structures, 2007, Vol. 29, pp. 904-913.

[18] Chen, Z.Y., Ge, H.B., Kasai, A. and Usami, T., "Simplified Seismic Design Approach for Steel Portal Frame Piers with Hysteretic Dampers", Earthquake Engineering and Structural Dynamics, 2007, Vol. 36, No. 4, pp. 541-562.

[19] JRA, "Design Specification of Highway Bridges. Part V: Seismic design", Japan Road Association, Tokyo, Japan, 2002, (in Japanese).

[20] SAC., "Develop Suites of Time Histories, SAC Joint Venture Steel Project Phase2: Project Task 5.4.1", Draft Report prepared by Woodward-Clyde Federal Services, Pasadena, CA, 1997.

[21] Ye, L.P., and Ouyang, Y.F., "Dual Seismic Structure System and its Parametric Analysis", Engineering Mechanics, 2000, Vol. 17, No. 2, pp. 23-29.

[22] Usami, T. ed., "Guidelines for Seismic and Damage Control Design of Steel Bridges", Japanese Society of Steel Construction, Gihodo Shuppan, Tokyo, Japan, 2006 (in Japanese). 


\section{Appendix A}

In the simplified model, temperature effect should be considered in transformation stress determination. In the text, SMA material constants at $T_{0}=40^{\circ} \mathrm{C}$ is cited from Ref. [17]. According to the formualtions in Ref. [17], considering the SMA tranformation constant of $5.6 \mathrm{MPa} /{ }^{\circ} \mathrm{C}$, if $T_{0}$ $=25^{\circ} \mathrm{C}$, the four transformation stresses would decrease nearly $84 \mathrm{MPa}$, as listed in Table A-1.

Take the case of S-F10 under JRT-EW-M accelerogram as example, the SMA damper was redesigned by Eqs. 8-16 in the paper with the same strength ratio and stiffness ratio, new dimensions of SMA damper are listed in Table A-2.

The performance investigation is illustrated as shown in Figure A-1. At the same level of strength ratio and stiffness ratio, it is found that similar structural responses existed in the structures with SMA dampers at $T_{0}=40^{\circ} \mathrm{C}$ and at $T_{0}=25^{\circ} \mathrm{C}$. It might be concluded that the conclusion of the paper would not have much difference by using the material constants at $T_{0}=40^{\circ} \mathrm{C}$.

Table A-1. Material constants of SMAs at $T_{0}=40^{\circ} \mathrm{C}$ and $T_{0}=25^{\circ} \mathrm{C}$

\begin{tabular}{|c|c|c|c|c|}
\hline$T_{0}\left({ }^{\circ} \mathrm{C}\right)$ & $\sigma_{M S}(\mathrm{MPa})$ & $\sigma_{M F}(\mathrm{MPa})$ & $\sigma_{A S}(\mathrm{MPa})$ & $\sigma_{A F}(\mathrm{MPa})$ \\
\hline 40 & 235 & 325 & 210 & 100 \\
\hline 25 & 151 & 241 & 126 & 16 \\
\hline
\end{tabular}

Table A-2. Design parameters and dimensions of SMAs at $T_{0}=40^{\circ} \mathrm{C}$ and $T_{0}=25^{\circ} \mathrm{C}$

\begin{tabular}{|c|c|c|c|c|}
\hline$T_{0}\left({ }^{\circ} \mathrm{C}\right)$ & $A\left(\mathrm{~mm}^{2}\right)$ & $l_{S M A}(\mathrm{~mm})$ & $\alpha_{F}$ & $\alpha_{K}$ \\
\hline 40 & 4651 & 2358 & 1.0 & 6.41 \\
\hline 25 & 7238 & 3664 & 1.0 & 6.41 \\
\hline
\end{tabular}
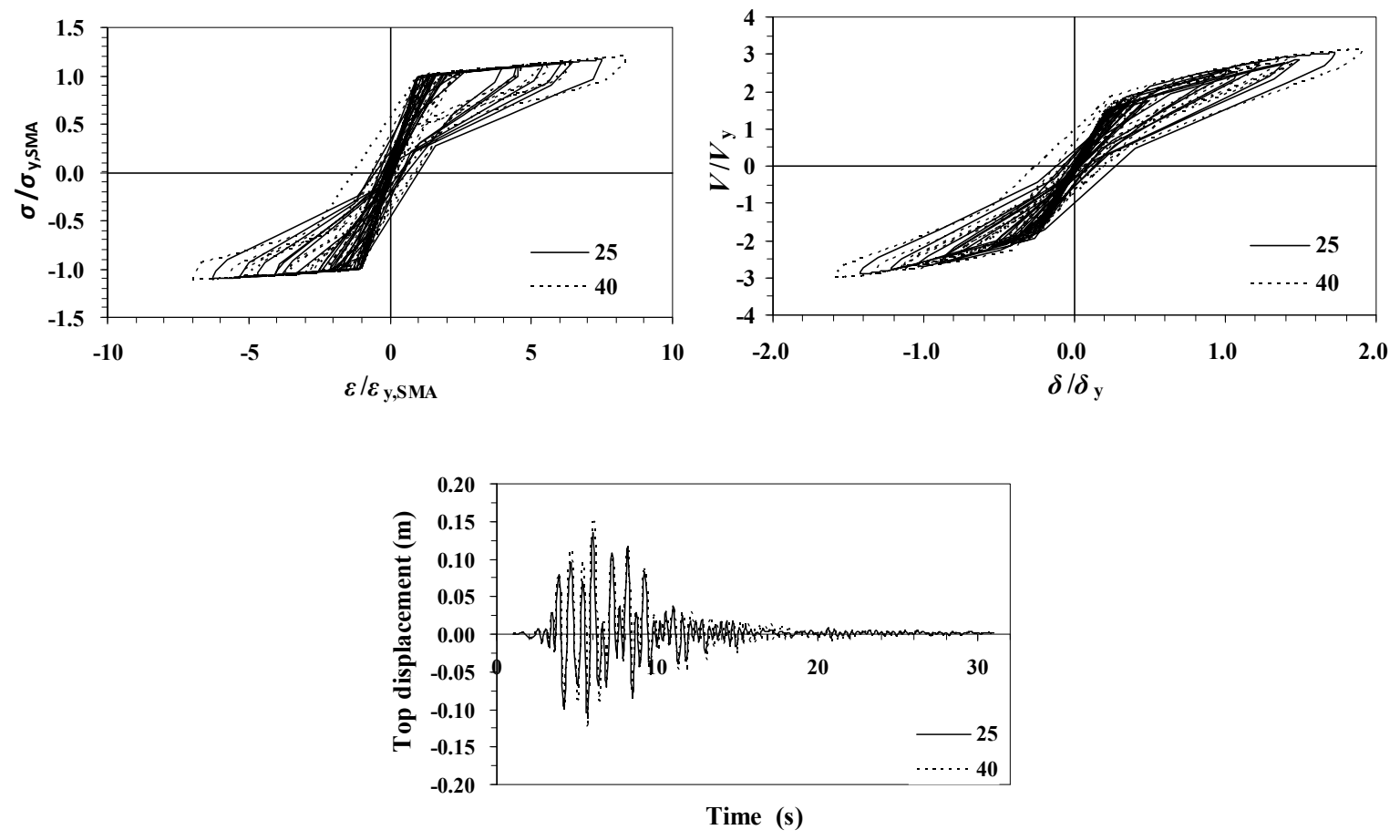

Figure A-1. Comparison of SMA Models with Material Constants at Different Reference Temperature 